Tersedia online di: http://ejournal-balitbang.kkp.go.id/index.php/jra

\title{
LAJU RESPIRASI INDUK IKAN BLACKHEAD SEABREAM Acanthopagrus schlegelii PADA SUHU PEMELIHARAAN YANG BERBEDA
}

\author{
Vitas Atmadi Prakoso*|* dan Young Jin Chang ${ }^{* *}$ \\ *) Balai Riset Perikanan Budidaya Air Tawar dan Penyuluhan Perikanan \\ * Institute of Review and Assesment on Fishery and Aquaculture, South Korea
}

(Naskah diterima: 31 Maret 2017; Revisi final: 26 Juli 2017; Disetujui publikasi: 26 Juli 2017)

\begin{abstract}
ABSTRAK
Laju respirasi hewan akuatik memiliki hubungan yang erat dengan metabolisme. Tingkat metabolisme hewan merupakan variabel yang dapat dipengaruhi faktor dalam maupun luar, salah satunya adalah suhu. Pada ikan, proses metabolisme juga berkorelasi dengan suhu. Salah satu jenis ikan yang perlu dikaji laju respirasinya adalah ikan blackhead seabream Acanthopagrus schlegelii yang merupakan spesies ikan laut yang popular di Korea Selatan, sehingga diperlukan lebih banyak informasi lagi mengenai laju respirasi ikan ini untuk mengoptimalkan metabolisme ikan ini dan berdampak kepada produktivitas budidaya. Penelitian ini bertujuan untuk mengevaluasi laju respirasi induk ikan blackhead seabream pada beberapa tingkatan suhu. Ikan blackhead seabream (panjang total 29,3 $\pm 2,2 \mathrm{~cm}$ dan bobot tubuh 538,3 $\pm 43,0 \mathrm{~g}$ ) diteliti menggunakan respirometer dalam sistem resirkulasi. Tiga kelompok percobaan dilakukan untuk mengukur laju respirasi berdasarkan perubahan suhu pemeliharaan $\left(15^{\circ} \mathrm{C}, 20^{\circ} \mathrm{C}\right.$, dan $\left.25^{\circ} \mathrm{C}\right)$. Hasil penelitian menunjukkan bahwa kecenderungan laju respirasi meningkat secara linier dengan peningkatan suhu perlakuan, dengan nilai tertinggi sebesar $164,8 \pm 30,7 \mathrm{mg} \mathrm{O}_{2} / \mathrm{kg} / \mathrm{jam}$ pada $25^{\circ} \mathrm{C}$ dan nilai terendah sebesar $72,4 \pm 8,1 \mathrm{mg} \mathrm{O} / 2 \mathrm{~kg} / \mathrm{jam}$ pada $15^{\circ} \mathrm{C}$. Sementara itu, frekuensi pernapasan berkorelasi positif terhadap kenaikan suhu. Berdasarkan penelitian ini, dapat disimpulkan bahwa perubahan suhu dari $15^{\circ} \mathrm{C}$ ke $25^{\circ} \mathrm{C}$ menyebabkan peningkatan laju respirasi pada induk ikan blackhead seabream.
\end{abstract}

\section{KATA KUNCl: blackhead seabream; Acanthopagrus schlegelii; suhu; laju respirasi}

ABSTRACT: Respiration rate of adult blackhead seabream Acanthopagrus schlegelii under different rearing temperatures. By: Vitas Atmadi Prakoso and Young Jin Chang

It is well known that a close relationship exists between respiration rateand metabolism in aquaticanimal. In fish, the metabolic rate is influenced by internal or external factors, such as temperature. This research observed the respiration rate of blackhead seabream, Acanthopagrus schlegelii, which is one of the popular marine fish species in South Korea. Despite the fish popularity, very few information are available about the fish's respiration rate which is important in order to optimize its metabolism and increase its aquaculture productivity. This study aimed to evaluate the respiration rate of adult blackhead seabream reared in media with different temperature settings. The fish (total length of 29.3 $\pm 2.2 \mathrm{~cm}$ and body weight of $538.3 \pm 43.0 \mathrm{~g}$ ) were observed using a respirometer placed inside the recirculation systems. Three groups of experiments wereset up to measure the fish's respiration rateaccording to different rearing temperatures $\left(15^{\circ} \mathrm{C}, 20^{\circ} \mathrm{C}\right.$, and $\left.25^{\circ} \mathrm{C}\right)$. The results showed that there was a tendency of respiration rate increased linearly with the increase of temperature. The highest respiration ratewas $164.8 \pm 30.7 \mathrm{mg} 02 / \mathrm{kg} / \mathrm{hour}$ at $25^{\circ} \mathrm{C}$ and the lowest value was $72.4 \pm 8.1 \mathrm{mg} 02 / \mathrm{kg} / \mathrm{hour}$ at $15^{\circ} \mathrm{C}$ which indicated that the respiratory rate positively correlated to the change in temperature. According to this study, it can be concluded that temperature changesfrom $15^{\circ} \mathrm{C}$ to $25^{\circ} \mathrm{C}$ led an increase in respiration rate of adult blackhead seabream

KEYWORDS: blackhead seabream; Acanthopagrus schlegelii; water temperature; respiration rate

\# Korespondensi: Balai Riset Perikanan Budidaya Air Tawar dan

Penyuluhan Perikanan. Jl. Sempur No. 1, Bogor 16154,

Indonesia. Tel. + (0251) 8313200

E-mail: vitas.atmadi@gmail.com 


\section{PENDAHULUAN}

Kebanyakan hewan tergantung pada ketersediaan oksigen untuk setidaknya di beberapa bagian dari kehidupan mereka. Bahkan hewan yang telah beradaptasi untuk hidup di habitat yang anoksik biasanya hanya bersifat anaerob fakultatif (Tielens et al., 2002;. Mentel \& Martin, 2010). Oksigen merupakan salah satu faktor yang paling penting dalam budidaya dan kebutuhan oksigen dari organisme akuatik juga berhubungan dengan metabolisme. Tingkat metabolisme hewan merupakan variabel yang dapat dipengaruhi dari dalam (bobot tubuh sifat fisiologis) maupun luar (misalnya ketersediaan oksigen, suhu, dan asupan makanan) (Chabot et al., 2016; Rosewarne et al., 2016). Saat ini, tingkat metabolisme menjadi salah satu ciri fisiologis yang paling banyak dipelajari pada hewan (White et al., 2013).

Proses metabolisme pada ikan ini juga berhubungan erat dengan suhu. Seperti sebagian besar reaksi biokimia, reaksi metabolisme aerobik secara langsung dipengaruhi oleh suhu lingkungan (Hochachka $\&$ Somero, 2002), sehingga organisme harus memiliki mekanisme untuk mengatasi efek ini untuk menyediakan energi yang diperlukan terhadap suhu lingkungan. Laju metabolisme hewan ectothermic biasanya memiliki korelasi positif dengan suhu. Hal tersebut karena efek Van't Hoff, di mana laju reaksi biokimia meningkat secara eksponensial dengan suhu (Marshall \& McQuaid, 2011; Branch \& Newell, 1978). Suhu yang lebih tinggi meningkatkan proporsi enzim yang telah mencapai tingkat energi aktivasi mereka, yang mempercepat laju rata-rata reaksi biokimia sehingga memungkinkan lebih banyak aktivitas (Houlihan \& Innes, 1984) dan membutuhkan oksigen yang lebih banyak (Bartholomew \& Casey, 1977). Oleh karena itu, laju metabolisme hewan ectothermic berkaitan erat dengan suhu, karena suhu mengatur routine metabolic rate (RMR) dan secara tidak langsung memicu active metabolic rate (AMR). Pada kebanyakan hewan air, tingkat metabolisme aerobik dapat diperkirakan secara tidak langsung dari pengukuran tingkat konsumsi oksigen atau laju respirasi. Penelitian tentang laju respirasi dalam kaitannya dengan suhu juga terus dikembangkan untuk keperluan budidaya pada berbagai spesies (Gillooly et al., 2001; Sarma et al., 2010; Turker, 2011; Tirsgaard et al., 2015; Prakoso et al., 2016).

Blackhead seabream Acanthopagrus schlegelii merupakan salah satu spesies ikan laut yang memiliki harga jual tinggi. Ikan ini populer di negara Korea Selatan sebagai ikan konsumsi, baik olahan maupun dalam bentuk sashimi. Dalam peningkatan produktivitas spesies ini, diperlukan lebih banyak informasi mengenai faktor-faktor lingkungan yang berkaitan dengan aspek fisiologinya. Salah satu aspek yang perlu dikaji adalah laju respirasinya terhadap beberapa tingkatan suhu yang berbeda. Beberapa penelitian terkait laju respirasi pada ikan blackhead seabream ini telah dipelajari (Chang et al., 2005; Jeong et al., 2007). Akan tetapi, penelitian tersebut dilakukan hanya pada ikan berukuran benih sampai $250 \mathrm{~g}$. Masih belum cukup informasi mengenai laju respirasi ikan ini pada ukuran induk untuk keperluan budidaya agar diketahui kondisi metabolisme optimalnya. Berdasarkan informasi tersebut, penelitian ini bertujuan untuk mengevaluasi laju respirasi induk ikan blackhead seabream pada beberapa tingkatan suhu.

\section{BAHAN DAN METODE}

Penelitian ini dilakukan di Laboratorium of Fish Reproductive and Biology, Pukyong National University, Busan, Korea Selatan. Ikan uji yang digunakan dalam penelitian ini yaitu induk ikan blackhead seabream sebanyak sembilan ekor, dengan kisaran panjang total 29,3 $\pm 2,2 \mathrm{~cm}$ dan bobot tubuh 538,3 $\pm 43,0 \mathrm{~g}$. Sebelum percobaan dimulai, ikan dipelihara di dalam sistem resirkulasi indoor dan diberi pakan sebanyak 2\%dari bo bot tubuhnya dengan menggunakan pakan komersial. Pakan diberikan pada pagi dan sore hari. Satu hari sebelum percobaan, ikan dipuasakan selama 24 jam untuk menghindari pengaruh pakan yang telah diberikan terhadap metabolisme ikan. Panjang dan bobot tubuh ikan uji diukur dan dicatat. Percobaan suhu yang dilakukan yaitu $15^{\circ} \mathrm{C}, 20^{\circ} \mathrm{C}$, dan $25^{\circ} \mathrm{C}$. Suhu pada masing-masing perlakuan diatur agar tetap stabil dengan menggunakan circulating water bath (JS-WBP170RP, Johnsam Co., Bucheon, Korea). Pengukuran suhu dilakukan menggunakan probesuhu yang terdapat di dalam sistem monitoring pengukuran laju respirasi (OxyGuard 6, OxyGuard International A/S, Birkerd, Denmark) dengan tingkat ketelitian $0,1^{\circ} \mathrm{C}$. Masingmasing perlakuan dilakukan pada pemeliharaan dengan salinitas 35 psu (Tabel 1). Selama perlakuan, fotoperiode diatur pada kondisi 12 jam terang: 12 jam gelap.

Ikan diletakkan di dalam respirometer berukuran $20 \mathrm{~cm} \times 30 \mathrm{~cm} \times 20 \mathrm{~cm}$ selama tiga jam sebelum percobaan agar aktivitasnya stabil. Respirometer untuk pengukuran laju respirasi ikan terletak di dalam sistem resirkulasi tertutup. Perhitungan dan pengukuran laju respirasi yang dilakukan pada penelitian ini mengadopsi metode pengukuran pada penelitian yang telah dilakukan oleh Chang et al. (2005). Nilai laju respirasi berdasarkan perbedaan suhu yang diperoleh merupakan nilai rata-rata \pm SD dari pengukuran selama 24 jam $(n=24)$. Sementara itu, nilai laju respirasi berdasarkan perbedaan fotoperiode 
Tabel 1. Perlakuan suhu pada percobaan laju respirasi ikan blackhead seabream (Acanthopagrus schlegelii)

Table 1. Water temperature treatments in respiration rate study of blackhead seabream (Acanthopagrus schlegelii)

\begin{tabular}{ccccc}
\hline $\begin{array}{c}\text { Percobaan } \\
\text { Experiment }\end{array}$ & $\begin{array}{c}\text { Salinitas (psu) } \\
\text { Salinity (psu) }\end{array}$ & $\begin{array}{c}\text { Suhu air }\left({ }^{\circ} \mathrm{C}\right) \\
\text { Water temperature }\left({ }^{\circ} \mathrm{C}\right)\end{array}$ & $\begin{array}{c}\text { Jumlah ikan (ekor) } \\
\text { Fish number (individu) }\end{array}$ & $\begin{array}{c}\text { Ulangan } \\
\text { Replication }\end{array}$ \\
\hline I & 35 & $15 \pm 0.3$ & 1 & 3 \\
II & 35 & $20 \pm 0.3$ & 1 & 3 \\
III & 35 & $25 \pm 0.3$ & 1 & 3 \\
\hline
\end{tabular}

(12 jam terang : 12 jam gelap) merupakan nilai ratarata \pm SD dari pengukuran selama 12 jam pada masingmasing periode $(n=12)$. Frekuensi bernapas induk ikan blackhead seabream dihitung berdasarkan jumlah gerakan buka tutup operkulum berdasarkan metode pada penelitian Wares \& Igram (1979). Semua data dianalisis dengan menggunakan software statistik PASW Statistics 18.

\section{HASIL DAN BAHASAN}

Suhu memengaruhi semua reaksi biokimia dalam tubuh dan memiliki dampak yang signifikan terhadap fisiologi dari organisme tersebut. Oleh karena itu, penelitian mengenai toleransi terhadap suhu dan pengaruhnya terhadap kesehatan ikan menjadi hal yang penting dalam penelitian akhir-akhir ini. Seperti ditunjukkan pada Tabel 2, laju respirasi induk ikan blackhead seabream di setiap perlakuan menunjukkan perbedaan yang signifikan antara perlakuan suhu $15^{\circ} \mathrm{C}$ dengan $20^{\circ} \mathrm{C}(\mathrm{P}<0,01)$, sedangkan pada perlakuan suhu $20^{\circ} \mathrm{C}$ dengan $25^{\circ} \mathrm{C}$ tidak ditemukan perbedaan yang signifikan $(P>0,01)$. Kecenderungan konsumsi oksigen meningkat secara linier dengan peningkatan suhu perlakuan, dengan nilai tertinggi sebesar 164,8 $\pm 30,7 \mathrm{mg} \mathrm{O}_{2} / \mathrm{kg} / \mathrm{jam}$ pada $25^{\circ} \mathrm{C}$ dan nilai terendah sebesar $72,4 \pm 8,1 \mathrm{mg} 0_{2} / \mathrm{kg} / \mathrm{jam}$ pada $15^{\circ} \mathrm{C}$.

Frekuensi pernapasan induk ikan blackhead seabream dari semua perlakuan ditunjukkan pada Gambar 1. Slope regresi linear frekuensi pernapasan berdasarkan perlakuan suhu yang berbeda pada induk ikan blackhead seabream yaitu 4,20. Nilai-nilai ini menunjukkan bahwa peningkatan frekuensi pernapasan berkorelasi positif dengan kenaikan suhu sampai dengan suhu optimal pemeliharaan bagi induk ikan blackhead seabream.

Metabolisme adalah proses fisiologis yang mencerminkan pengeluaran energi dari organisme hidup. Tingkat metabolisme ikan biasanya secara tidak langsung diukur melalui laju respirasi. Dalam penelitian ini, laju respirasi meningkat secara signifikan dengan meningkatnya suhu dari $15^{\circ} \mathrm{C}$ ke $25^{\circ} \mathrm{C}$, menunjukkan peningkatan total metabolisme aerobik dengan adanya kenaikan suhu (Kutty \& Mohamed, 1975).

Tabel 2. Laju respirasi induk ikan blackhead seabream Acanthopagrus schlegelii pada suhu pemeliharaan yang berbeda

Table 2. Respiration rate of adult blackhead seabream Acanthopagrus schlegelii under different rearing temperatures

\begin{tabular}{|c|c|c|}
\hline $\begin{array}{r}\text { Sul } \\
\text { Water te }\end{array}$ & $\begin{array}{l}\text { uhu air }\left({ }^{\circ} \mathrm{C}\right) \\
\text { temperature }\left({ }^{\circ} \mathrm{C}\right)\end{array}$ & $\begin{array}{l}\text { Laju respirasi }\left(\mathrm{mg} \mathrm{O}_{2} / \mathrm{kg} / \mathrm{jam}\right) \\
\text { Respiration rate }\left(\mathrm{mg} \mathrm{O}_{2} / \mathrm{kg} / \mathrm{hour}\right)\end{array}$ \\
\hline & 15 & $72.4 \pm 8.1^{b}$ \\
\hline & 20 & $124.2 \pm 20.7^{a}$ \\
\hline & 25 & $164.8 \pm 30.7^{\mathrm{a}}$ \\
\hline \multicolumn{3}{|c|}{$\begin{aligned} \text { Keterangan: } & \text { Masing-masing nilai merupakan rata-rata } \pm \text { SD }(n=24) \text {. } \\
& \text { Perbedaan huruf yang dicetak atas (superscript) } \\
& \text { mengindikasikan adanya perbedaan yang signifikan antar } \\
& \text { perlakuan }(P<0,01)\end{aligned}$} \\
\hline \multicolumn{3}{|c|}{ 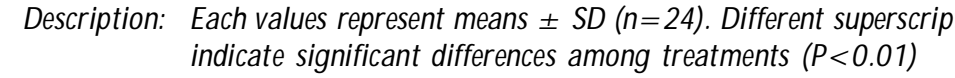 } \\
\hline
\end{tabular}



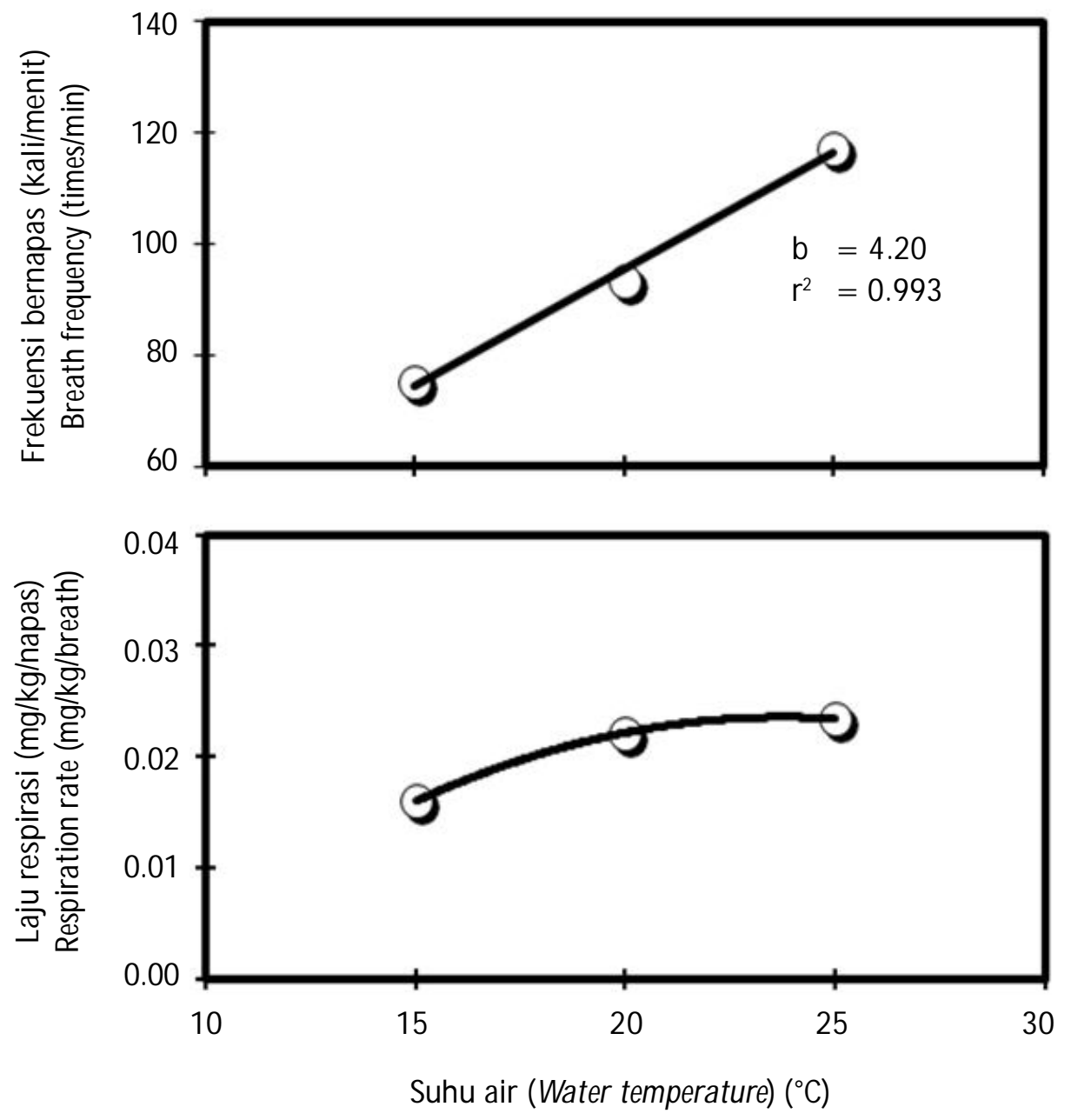

Gambar 1. Frekuensi bernapas per menit dan laju respirasi per satu kali tarikan napas pada induk ikan blackhead seabream Acanthopagrus schlegelii dalam beberapa suhu pemeliharaan yang berbeda $\left(15^{\circ} \mathrm{C}, 20^{\circ} \mathrm{C}\right.$, dan $25^{\circ} \mathrm{C}$ ).

Figure 1. Breath frequency per minute and respiration rate per breath on adult blackhead seabream Acanthopagrus schlegelii in different rearing temperatures $\left(15^{\circ} \mathrm{C}, 20^{\circ} \mathrm{C}\right.$, and $\left.25^{\circ} \mathrm{C}\right)$.

Dalam penelitian ini, laju respirasi dari induk ikan blackhead seabream dipengaruhi oleh peningkatan suhu. Hasil ini sesuai dengan penelitian pada beberapa spesies terhadap kenaikan suhu (Oh et al., 2006; 2010; Turker, 2011; Prakoso et al., 2015; 2016). Gardner \& King (1922) dan Chang et al. (2005) juga melaporkan bahwa kebutuhan oksigen pada ikan meningkat secara linear dengan kenaikan suhu. Selain itu, hasil penelitian sebelumnya menyebutkan bahwa laju respirasi pada spesies yang sama dengan ukuran dan bobot tubuh yang lebih kecil yaitu sebesar $140,0 \pm 38,3 ; 174,8 \pm$ 52,3 ; dan $282,3 \pm 53,8 \mathrm{mg} \mathrm{O} / \mathrm{kg} / \mathrm{jam}$ pada suhu $15^{\circ} \mathrm{C}$, $20^{\circ} \mathrm{C}$, dan $25^{\circ} \mathrm{C}$ (Jeong et al., 2007). Jika dibandingkan dengan hasil yang diperoleh pada penelitian saat ini, laju respirasi induk ikan blackhead seabream memiliki nilai yang lebih rendah. Hal ini menunjukkan bahwa laju respirasi ikan blackhead seabream mengalami penurunan dengan semakin besarnya bobot tubuh ikan. Hasil tersebut sesuai dengan beberapa penelitian terdahulu pada beberapa spesies ikan lainnya, yaitu Carassius auratus, Paralichthys olivaceus, Sebastes schlegeli, Takifugu rubripes, Lateolabrax japonicus, dan Pagrus major yang juga menyatakan bahwa semakin besar bobot tubuh ikan akan mengakibatkan penurunan laju respirasi pada individu tersebut (Beamish \& Mookherjii, 1964; Kim et al., 1995; Chang et al., 2005).

Laju respirasi dari induk ikan blackhead seabream di setiap perlakuan suhu saat siang lebih tinggi dibandingkan malam (Tabel 3). Nilai rata-rata dari laju respirasi saat siang hari $14,37 \%$ lebih besar pada $15^{\circ} \mathrm{C}$; 
Tabel 3. Laju respirasi induk ikan blackhead seabream Acanthopagrus schlegelii pada suhu pemeliharaan yang berbeda saat siang dan malam

Table 3. Respiration rate of adult blackhead seabream Acanthopagrus schlegelii under different rearing temperatures during day and night

\begin{tabular}{|c|c|c|}
\hline \multirow{2}{*}{$\begin{array}{c}\text { Suhu air }\left({ }^{\circ} \mathrm{C}\right) \\
\text { Water temperature }\left({ }^{\circ} \mathrm{C}\right)\end{array}$} & \multicolumn{2}{|c|}{$\begin{array}{l}\left.\text { Laju respirasi ( } \mathrm{mg} \mathrm{O}_{2} / \mathrm{kg} / \mathrm{jam}\right) \\
\text { Respiration rate }\left(\mathrm{mg} \mathrm{O}_{2} / \mathrm{kg} / \text { hour}\right)\end{array}$} \\
\hline & Siang (Day) & Malam (Night) \\
\hline 15 & $77.2 \pm 8.7^{c}$ & $67.5 \pm 2.8^{c}$ \\
\hline 20 & $135.5 \pm 22.9^{\mathrm{ab}}$ & $112.9 \pm 9.5^{b}$ \\
\hline 25 & $182.8 \pm 32.3^{\mathrm{a}}$ & $146.8 \pm 14.7^{\mathrm{a}}$ \\
\hline
\end{tabular}

Keterangan: Masing-masing nilai merupakan rata-rata \pm SD $(n=12)$. Perbedaan huruf yang dicetak atas (superscript) antar kolom mengindikasikan adanya perbedaan yang signifikan antar perlakuan $(P<0,01)$

Description: Each values represent means $\pm S D(n=12)$. Different superscript between columns indicate significant differences among treatments $(P<0.01)$

$20,01 \%$ lebih besar pada $20^{\circ} \mathrm{C}$; dan 24,52\%lebih besar pada $25^{\circ} \mathrm{C}$ dibandingkan malam hari. Akan tetapi, tidak ditemukan adanya perbedaan signifikan dari laju respirasi induk ikan blackhead seabream saat siang dan malam di setiap suhu pemeliharaan $(P>0,01)$.

Dalam penelitian ini, rata-rata laju respirasi saat siang lebih tinggi daripada malam pada setiap suhu perlakuan. Beamish \& Mookherjii (1964) melaporkan bahwa laju respirasi ikan mencerminkan aktivitas ikan itu sendiri. Berkaitan dengan itu, ikan blackhead seabream tampaknya lebih aktif pada siang hari dibanding malam hari, seperti banyak spesies ikan pada umumnya yg telah diteliti (Lim et al., 2004; Biswas et al., 2010; Oh et al., 2010) dan berbanding terbalik dengan ikan yang aktif pada malam hari (Byun et al., 2008).

Kedua faktor tingkah laku dan fisiologis dapat memengaruhi bagaimana suhu memengaruhi tingkat aktivitas dan active metabolic rate dari hewan ectothermic. Dari perspektif tingkah laku, misalnya pada suhu di mana kemungkinannya tinggi untuk mendapatkan makanan, hewan dapat meningkatkan tingkat aktivitas mereka untuk memaksimalkan asupan energi (Speakman, 1986) atau alternatif lainnya mereka mungkin menjadi kurang aktif, misalnya karena banyak terdapat predator (Anholt et al., 2000; Werner \& Anholt, 1993). Sedangkan dari perspektif fisiologis, ada efek langsung dari suhu pada reaksi biokimia yang terlibat dalam gerak (Halsey et al., 2015).

\section{KESIMPULAN}

Berdasarkan hasil penelitian ini, peningkatan suhu dari $15^{\circ} \mathrm{C}$ ke $25^{\circ} \mathrm{C}$ menyebabkan kenaikan laju respirasi pada induk ikan blackhead seabream

\section{UCAPAN TERIMA KASIH}

Penulis mengucapkan terima kasih kepada Kitae Kim dan Jun-Hyung Ryu atas kontribusinya selama penelitian berlangsung. Serta kepada KOICA dan Pukyong National University atas fasilitas yang diberikan selama penelitian ini berlangsung.

\section{DAFTAR ACUAN}

Anholt, B.R., Werner, E., \& Skelly, D.K. (2000). Effect of food and predators on the activity of four larval ranid frogs. Ecology, 81, 3509-3521.

Beamish, F.W.H. \& Mookherjii, P.S. (1964). Respiration of fishes with special emphasis on standard oxygen consumption. II. Influence of weight and temperature on respiration of goldfish, Carassius auratus L. Canadian Journal of Zoology, 42, 161175.

Bartholomew, G.A. \& Casey, T. (1977). Endothermy during terrestrial activity in large beetles. Science, 195, 882-883.

Biswas, A., Kazushige, I., \& Takii, K. (2010). Feeding interval and photoperiod influence the growth performance of striped knifejaw, Oplegnathus fasciatus. Aquaculture Research, 41, 517-523. 
Branch, G.M. \& Newell, R.C. (1978) A comparative study of metabolic energy expenditure in the limpets Patella cochlear, P. oculus, and P. granularis. Marine Biology, 49, 351-361.

Byun, S.G., Jeong, M.H., Lee, J.H., Lee, B.I., Ku, H.D., Park, S.U., Kim, Y.C., \& Chang, Y.J. (2008). Diel rhythm of oxygen consumption of the starry flounder Platichthys stellatus by water temperature. Journal of Korean Fisheries Society, 41, 113-118.

Chabot, D., Steffensen, J.F., \& Farrell, A.P. (2016). The determination of standard metabolic rate in fishes. Journal of Fish Biology, 88, 81-121.

Chang, Y.J., Jeong, M.H., Min, B.H., Neill, W.H., \& Fontaine, L.P. (2005). Effect of photoperiod, temperature, and fish size on oxygen consumption in the black porgy Acanthopagrus schlegelii. Journal of Fish Science and Technology, 8, 142-150.

Gardner, J.A. \& King, G. (1922). Respiratory exchange in freshwater fish, further comparison of goldfish and trout. Biochemical Journal, 16, 729-735.

Gillooly, J.F., Brown, J.H., West, G.B., Savage, V.M., \& Charnov, E.L. (2001). Effects of size and temperature on metabolic rate. Science, 293, 2248-2251.

Halsey, L.G., Matthews, P.G.D., Rezende, E.L., Chauvaud, L., \& Robson, A.A. (2015). The interactions between temperature and activity levels in driving metabolic rate: theory, with empirical validation from contrasting ectotherms. Oecologia, $13 p p$.

Hochachka, P.W. \& Somero, G.N. (2002). Biochemical adaptation: Mechanism and process in physiological evolution. New York: Oxford University Press.

Houlihan, D. \& Innes, A. (1984). The cost of walking in crabs: aerial and aquatic oxygen consumption during activity of two species of intertidal crab. Comparative Biochemistry and Physiology Part A, 77, 325-334.

Jeong, M.H., Kim, Y.S., Min, B.H., \& Chang, Y.J. (2007). Effect of fish number in respiratory chamber on routine oxygen consumption of black porgy Acanthopagrus schlegelii reared in seawater or freshwater. Journal of Aquaculture, 20, 121-126.

Kim, I.N., Chang, Y.J., \& Kwon, J.Y. (1995). The patterns of oxygen consumption in six species of marine fish. Journal of Korean Fisheries Society, 28(3), 373-381.

Kutty, M.N. \& Mohamed, M.P. (1975). Metabolic adaptations of mullets Rhinomugil corsula (Hamilton) with special reference to energy utilization. Aquaculture, 5, 253-270.

Lim, H.K., Jeong, M.H., Han, H.K., Lee, J.H., \& Chang, Y.J. (2004). Oxygen consumption of hybrid stripped bass (M orone chrysops @ \& $\times$ M. saxatilis $B \&$ ) exposed to different temperature, salinity and photoperiod. Journal of Aquaculture, 17, 258-261.

Marshall, D.J., \& MCQuaid, C.D. (2011). Warming reduces metabolic rate in marine snails: adaptation to fluctuating high temperatures challenges the metabolic theory of ecology. Proceedings of the Royal Society B, 278, 281-288.

Mentel, M., \& Martin, W. (2010). Anaerobic animals from an ancient, anoxic ecological niche. BMC Biology, 8, 32.

Oh, S.Y., Noh, C.H. Kang, R.S., \& Myoung, J.G. (2006). Effect of water temperature and photoperiod on the oxygen consumption rate of fasted juvenile parrot fish, Oplegnathus fasciatus. Ocean and Polar Research, 28, 407-413.

Oh, S.Y., Park, H.S., \& Kim, C.K. (2010). Effect of water temperature and photoperiod on the oxygen consumption rate of juvenile Pacific cod, Gadus macrocephalus. Ocean and Polar Research, 32, 229236.

Prakoso, V.A., Kim, K.T., Min, B.H., Gustiano, R., \& Chang, Y.J. (2015). Effects of salinity on oxygen consumption and blood properties of young grey mullets M ugil cephalus. Indonesian Aquaculture Journal, 10(2), 143-153.

Prakoso, V.A., Ryu, J.H., Min, B.H., Gustiano, R., \& Chang, Y.J. (2016). Oxygen consumption of rockbream Oplegnathus fasciatus in different salinity levels and temperature degrees. Berita Biologi, 15(2), 167-173.

Rosewarne, P.J., Wilson, J.M., \& Svendsen, J.C. (2016). Measuring maximum and standard metabolic rates using intermittent-flow respirometry: a student laboratory investigation of aerobic metabolic scope and environmental hypoxia in aquatic breathers. Journal of Fish Biology, 88, 265-283.

Sarma, K., Pal, A.K., Ayyappan, S., Das, T., Manush, S.M., Debnath, D., \& Baruah, K. (2010). Acclimation of Anabas testudineus (Bloch) to three test temperatures influences thermal tolerance and oxygen consumption. Fish Physiology and Biochemistry, 36, 85-90.

Speakman, J.R. (1986). The optimum search speed of terrestrial predators when feeding on sedentary prey: a predictive model. Journal of Theoretical Biology, 122, 401-407.

Tielens, A.G.M., Rotte, C., van Hellemond, J.J., \& Martin, W. (2002). Mitochondria as we don't know them. Trends in Biochemical Sciences, 27, 564-572.

Tirsgaard, B., Svendsen, J.C., \& Steffensen, J.F. (2015). Effects of temperature on specific dynamic action 
in Atlantic cod Gadus morhua. Fish Physiology and Biochemistry, 41, 41-50.

Turker, H. (2011). The effect of water temperature on standard and routine metabolic rate in two different sizes of nile tilapia. Kafkas Universitesi Veteriner Fakultesi Dergisi, 17, 575-580.

Wares, W.D. \& Igram, R. (1979). Oxygen consumption in the fathead minnow (Pimephales promelas Rafinesque), effects of weight, temperature, group size, oxygen level, and opercular movement rate as a function of temperature. Comparative Biochemistry and Physiology, 62, 351-356.

Werner, E.E. \& Anholt, B.R. (1993). Ecological consequences of the tradeoff between growth and mortality rates mediated by foraging activity. American Naturalist, 142, 242-272.

White, C.R., Schimpf, N.G., \& Cassey, P. (2013). The repeatability of metabolic rate declines with time. Journal of Experimental Biology, 216:1763-1765. 